\title{
EnTREVISTA VÂnIA PEnHA-IOPES
}

\section{Entrevistadores: Carolina Ribeiro e Roberto Jardim}

A Sociologias Plurais entrevistou a professora Vânia Penha-Lopes que aceitou conversar conosco enquanto ministrava o mini curso RELAÇÕES RACIAIS COMPARADAS: BRASIL E EUA, promovido pelo Programa de Pós-Graduação em Sociologia (PGSOCIO/UFPR); Núcleo de Estudos de Gênero (NEG/UFPR); Núcleo de Estudos Afro-Brasileiros (NEAB/UFPR); Programa de Pós-Graduação em Educação (PPGE/UFPR) e o Instituto de Estudos Avançado de Mobilidade Social. Vânia Penha-Lopes, Ph.D., é professora titular de Sociologia no Bloomfield College, em Nova Jérsei, EUA e, desde 2010, codiretora do Seminário do Brasil na Universidade Columbia, em Nova lorque, também é membro do comitê executivo da Brazilian Studies Association-BRASA. É doutora em Sociologia pela Universidade de Nova Iorque (1999), com pós-doutorado em Ciências Sociais do Programa de Pós-graduação em Ciências Sociais da Universidade do Estado do Rio de Janeiro (2007). É também mestra em Sociologia (1991) e em Antropologia (1987), ambos pela Universidade de Nova lorque, e bacharel em Ciências Sociais pela Universidade Federal do Rio de Janeiro (1982, com distinção acadêmica). A Professora Doutora Vânia é congressista e palestrante na América do Norte, América do Sul e Europa e é autora de vários artigos, em inglês e português, sobre relações raciais no Brasil e nos Estados Unidos, ações afirmativas comparadas, família e masculinidades. Durante sua passagem pelo Brasil em 2013, Vânia Penha-Lopes lançou o livro "Pioneiros: Cotistas na Universidade Brasileira" pela Paco Editorial.

Sociologins Plurais. Como você vê o campo da Sociologia nos Estados Unidos, em especial nas áreas de estudos raciais e étnicos e a área de estudos de gênero, pensando especialmente em comparação a essas mesmas áreas no Brasil?

Vânin. Eu lido com professores brasileiros, eu mantenho uma agenda intelectual no Brasil e os meus colegas do Brasil estudam raça também. Não posso falar sobre o Brasil todo, mas a impressão que eu tenho, estudando o tema de ações afirmativas desde 2002, é que houve uma revitalização de estudos de raça no Brasil, pois sempre houve uma discussão, para mim a discussão nunca acabou, mas ela ganhou um novo ímpeto com as políticas públicas. No Rio de Janeiro, o fato da UERJ ter sido a primeira a implantar as políticas, a discussão acontece nos jornais, não é só no meio acadêmico, 
está na mídia o tempo todo; mas no meio acadêmico também tem muita produção sobre isso. Também na UnB encontramos muitas discussões sobre estudos raciais e étnicos. Em São Paulo, também, de certa forma, com o Antônio Sérgio Guimarães e Valter Silvério. Na Bahia, temos a UFBA e o NEV promove essas discussões todas. Então, eu acredito que são lugares, tirando São Paulo, porque tem menos negros, mas Rio e na Bahia são lugares onde a presença negra é maior do que aqui no Paraná. Pensando agora essa área em comparação com os EUA, raça é um conceito tão fundamental lá quanto aqui, e existe uma tradição muito, muito longa e rica de estudos sobre raça. Temos, por exemplo, as teorias pseudocientíficas do século XIX, também no começo do século XX tem muita produção, mas ainda muito racista; saíram de pessoas que claramente eram eugenistas, mas tem pessoas como o Du Bois. Penso que ele se formou em 1895 em Harvard e ele praticamente começa os estudos de raça, porque chega a trabalhar com a Escola de Chicago, mas na Escola de Chicago eram estudados os imigrantes, aí se comparava os imigrantes uns com os outros, mas os negros não tinham uma presença forte em Chicago. Na virada do século XIX para o XX, Du Bois realizou um estudo do negro da Filadélfia, e aquilo ali foi pioneiro, porque é um estudo estatístico de um bairro de uma região metropolitana da Filadélfia. Ele fez um trabalho de censo mesmo, mapeou as ruas, o número de casas, entrevistou as pessoas. Esse foi um trabalho que marcou a Sociologia americana e é sobre o negro. Depois Du Bois também fez um livro que é seminal, é um livro de ensaios, não é um livro metodológico de Sociologia, como o que citei antes, mas é um livro fundamental, em inglês chama The Souls of Black Folk, que seria As Almas dos Negros, do povo negro, mas não sei se foi traduzido oficialmente para 0 Brasil. Esse livro é de 1903 e, até hoje, é lido. Eu sou uma das pessoas que dá esse livro nos cursos, não no curso básico de raça e etnia, mas nos cursos mais avançados, todos tem que ler. Mas é um livro muito difícil, o Du Bois é muito difícil de ler, muito rebuscado, é um autor extremamente erudito e muito orgulhoso da erudição dele e ele falava várias línguas, então tem expressões em alemão, latim, francês e, muitas vezes, o aluno não procura 0 que quer dizer prejudicando a leitura e o entendimento. E é difícil de entender, também, porque ele estava na controvérsia com Washington que achava que os negros deviam fazer trabalhos manuais e não usar a cabeça, que era ideia bem que "nós não podemos", mas porque um negro não pode estudar gramática francesa? Du Bois escreveu nesse livro, porque não se pode estudar os clássicos? Pode sim, Então, tem alusões à mitologia grega, o que complica o entendimento se não for uma leitura atenta. Esse livro é 
lido até hoje nos EUA, quem estuda raça sempre se remete a esse livro, porque é nele que o Du Bois escreve, logo no comecinho do século XX: "O problema do século XX é o problema da linha da cor", "The problem of the twentieth century is the problem of the color line" e pronto! Porque isso fechou tudo, porque a gente pode hoje em dia falar: "Ah, mas hoje estamos no século XXI, o problema ainda é da linha de cor?" É, podemos dizer que sim. Não digo que nada tenha mudado, claro que muita coisa mudou, mas a cor ou a raça continua sendo um status mestre, então aquilo foi fundamental; e o livro é fininho, um livro tipo Estigma (de Goffman), fininho e difícil. Então tem esse "problema da cor" e o mais interessante é ele publicando esse livro em 1903, onde ele já diz: "e não é só nos EUA, isso é um problema mundial", ou seja, ele já está antecipando questões da globalização, do panafricanismo que vem muito depois, pelo menos uns 20,30 anos depois da obra dele, mas ele já estava pensando nisso, que são os povos colonizados, os povos africanos e asiáticos, que não são brancos, que são explorados pelos povos que são brancos, então é um trabalho pioneiro. Du Bois também fala em um dos ensaios sobre música negra, falando das sorrow songs, das músicas de lamentação, que fala das músicas que os escravos cantavam enquanto trabalhavam, que deram origem a tudo, ao Blues, ao Rock, tudo vem dali, aí ele escreve sobre elas. Tem um artigo sobre o filho dele, que morreu por falta de atendimento. Pois tanto os médicos negros quanto só médicos brancos não queriam atendê-lo com medo de serem acusados de cruzar a linha de cor. Os médicos negros poderiam ser linchados se o fizessem, e os médicos brancos se recusavam a cruzar a linha da brancura, de cor, porque o garoto era negro, embora fosse louro de olhos azuis. Então, tudo está ali. E, além disso, tem um ensaio sociológico sobre relações raciais nos EUA em geral e no sul em particular, então, num dos artigos por exemplo ele faz uma, uma abordagem sociohistórica das condições do sul depois das condições do negro no sul depois da abolição, então Du Bois diz: "depois da abolição, eles agora são livres mas eles não têm terra, então numa economia de agricultura, quem não tem terra é explorado", então ele conta como os negros são explorados, daí ali tem dados estatísticos, ele fala de divisão de classe entre os negros do sul, e isso é em 1903, mas tem uma série de livros. Oliver Cox, por exemplo, um autor marxista que achava que o racismo era uma condição do capitalismo. Cox tem um livro chamado Caste, Class and Race, no qual ele fala como os membros da classe dominante convencem as classes trabalhadoras de que elas são diferentes por causa da cor e é por isso que elas não se unem contra o capitalismo. É um argumento totalmente marxista. Cox também era negro. Ele é uma pessoa 
que, hoje em dia, não é muito mencionada, talvez por ele ter sido claramente comunista, porque os EUA é bem anticomunista. Embora eu não concorde com ele, nessa ideia da raça ser subordinada ao capitalismo, é um livro também que influenciou muita gente. $O$ que e quero dizer com isso é que em toda década, desde a virada do século XIX para o XX, em todas as décadas se pode reconhecer pelo menos um trabalho sobre relações raciais nos EUA; todas as décadas. E continuando hoje, um livro que ganhou o prêmio da Associação Americana de Sociologia, um livro excelente, escrito por Melvin L. Olivar e Thomas M. Shapiro. O Oliver é negro, o Shapeer é judeu branco. O título do livro é Black Wealth, White Wealth, Riqueza Branca, Riqueza Negra. É um livro que foi publicado entre 1995 e 1996. Um livro maravilhoso. Dois sociólogos que escreveram sobre porque que a classe média negra é diferente da classe média branca nos EUA, aí eles falam porquê né? É uma análise histórica também, porque aos negros não foram permitidos acumular capital, uma vez que o trabalho escravo fora apropriando por outrem. Quando acabou a escravidão eles não tiveram condições de se inserir no mercado de trabalho consistentemente e, por conseguinte, os herdeiros deles não herdaram nada além de dívidas. Esses pensadores fazem uma análise, de hábitos. Por exemplo, o fato das crianças de classe média branca crescerem ouvindo falar em investimentos, em ações, enquanto que as crianças negras são completamente ignorantes sobre isso porque os negros não tem investimentos. Eles analisam também de quanto em dinheiro o governo federal deve aos negros não só por causa da abolição mas porque depois disso, o governo federal não incluiu os negros nos incentivos, nos subsídios, no welfare. Então, eles não tiveram acesso a casa própria, a educação, mesmo até depois de 1964. As mudanças são recentes. Dos autores que discutem raça nos EUA tem também o William Julius Wilson que inclusive foi presidente da Associação Americana de Sociologia; ele é negro e trabalha a raça e classe. A raça nos Estados Unidos tem uma posição de destaque na disciplina, embora isso não quer dizer que todo mundo leia sobre. Pois quando eu estudei Sociologia da Família, fiz um curso de leitura nessa área e minha professora não sabia nada, nunca tinha lido nada sobre Sociologia da Família Negra. Há uma tradição longuíssima também, Dubois, E. Franklin Frazier, Moinehand, e Jesse Bernard, Carol Stack - a Carol Stack é antropóloga -, Andrew Belingslee, os Macdoo, que eram um casal, marido e mulher; olha quantos eu estou citando, e ela não tinha lido nenhum deles, nenhum. Então é claro que isso é uma atitude racista. Se você estuda família, você só estuda a norma [a família branca], mas enfim, o estudo está lá. E no meu caso também, eu queria estudar, mas no departamento da NYU 
não tinha ninguém que estudasse raça. Todos diziam que tinha que haver alguém da área dos estudos raciais. Hoje em dia tem, mas não tinha naquela época, contudo eu fiz minha tese de doutorado sobre homens negros, pois a professora permitiu que eu fizesse a pesquisa com esse tema, embora ela fosse especialista em gênero e família, mas não em raça. Resumindo: no país como um todo hoje, é uma área fértil.

Sociologins Plurnis. Bom, pelo que você relata parece mais fértil que aqui. Eu acho que talvez aqui, neste estado [Paraná], nesta cidade [Curitiba], é mais complicado também porque a cidade tem uma mentalidade do século XIX. É uma cidade que sofreu um processo de embranquecimento, na verdade, os negros daqui, eles moram na região metropolitana.

Vânio. Colombo [cidade da região metropolitana de Curitiba] não é? Eu já ouvi falar.

Sociologins Plurais. Eles não são bem vindos no centro, isso é evidente, isso é estrutural. Soa estranho perguntar em Curitiba "onde estão os negros? Onde estão as pessoas negras da cidade?".É uma palavra tabu aqui. É uma ausência, um não falar. $E$ as pessoas de Curitiba cresceram com isso. É bem interessante o processo de construção da identidade da cidade. Então, no Paraná, acho que essa exclusão, esse silêncio [sobre a questão racial], fez parte dessa ideia: "não vamos falar sobre isso também, não vamos falar sobre isso na academia, a gente não sabe onde eles estão".

Vânio. E tem um conceito chamado imigrante involuntário, que é do Lieberstan. As pessoas pensam em imigrante como aquelas pessoas que estavam fugindo ou que queriam melhores condições de vida. Saiu [de sua terra natal], mas optou por sair, mas os escravos também eram imigrantes, imigrantes involuntários. Eles foram arrancados de suas terras, as pessoas [dizem]: "ah, mas se a pessoa está passando dificuldade econômica, dificuldades econômicas no seu próprio país, não é uma questão de opção", é sim, porque a pessoa ainda tem a opção de escolher o local para onde imigrar, por exemplo, ir para o Brasil, para os EUA, ou ir para o Canadá. Agora o escravo não. "Olha, ouvi dizer que no Rio tem uma baia maravilhosa, que a enseada de Botafogo é linda, eu vou para lá, eu vou para lá em vez de ir para o nordeste que é muito quente". Não foi assim não. Eles vieram em navios, jogados. Então eles eram imigrantes involuntários, quer dizer, aqui no 
Paraná não se tem nem a ideia de negro como descendente também de imigrante, porque vieram de outro país e então imigraram.

Sociologins Plurais. A segunda pergunta segue nessa linha também: considerando o cenário acadêmico da Sociologia, qual a importância de se dialogar entre a tríade Gênero, Classe e Raça dentro dos estudos sociológicos?

Vânin. É algo que acho que é básico da Sociologia, e desde o fim dos anos 80 eu diria, que nos Estados Unidos se fala na intersecção dessas três categorias, que são básicas para a estratificação social. Essas 3 categorias existem separadamente, como conceito são distintos, mas como práxis, como convivência social é muito difícil separá-los, eu digo para meus alunos que ninguém tem opção de ser hoje só mulher, amanhã não, agora eu estou negra. Cada indivíduo já é o exercício daquela intersecção. Então, hoje em dia, nos EUA um acadêmico que escrevesse um trabalho - não que a pessoa tenha que ser especialista nas três áreas - mas que não leve em consideração essas áreas e a intersecção entre elas, seria muito, muito fácil de criticar [avaliar] o trabalho. A mulher tem pontos em comum com todas as mulheres, mas aí tem cada disparidade de classe, etnicidade e raça que não dá para falar na mulher, e geralmente quando falam "a mulher" estão falando na mulher branca, de classe média, porque quando é a mulher branca pobre, eles vão falar a mulher pobre. Então essa intersecção, a importância é de se abrir os olhos para o papel da normalidade, do normativo, porque quando não se fala se torna normativo. Se você não pensa [sobre isso] então é porque "ué, não é assim?", como "cadê os negros?" "ué, mas não é normal ter negro aqui, aqui todo mundo... aqui todo mundo é normal", ou seja, branco. Então é a mesma coisa nos estudos raciais, eu acho que é central.

Sociologins Plurnis. E pensar os estudos sociológicos considerando essa intersecção é ainda algo recente e que precisa ser amadurecido?

Vânin. O que me alertou para isso foi quando eu estava fazendo o curso de Sociologia da Família, que eu já, eu estava interessada em estudar homens, como eu falei, em estudar a masculinidade, e um livro, que é até um livro de, que eu não sei se aqui tem. É uma antologia, uma coletânea, o título era As vidas dos Homens, Men's Lives, e ele, no prefácio - e eu fiz um curso com um dos autores o Michael Kimmel, que é um expoente, o cara que 
praticamente começou estudos de masculinidades nos EUA - diz que numa aula dele uma aluna negra falou para uma aluna branca "quando você se olha no espelho o que que você vê?" "Uma mulher", e ela falou, "bom, quando eu me olho no espelho eu vejo uma mulher negra". Aí ele falou, é a mesma coisa com os homens. Então, o que a aluna queria dizer era: você vê a norma, uma mulher branca, mas o branco é a norma então nem se fala [de sua cor]; e os homens também, "Ah, eu sou homem". Mas as experiências dos homens negros, dos homens asiáticos nos EUA, são muito diferentes das dos brancos. Então, por exemplo, nos EUA não tem locutor asiático, tem locutora asiática, locutor não, eles fazem, eles são repórteres, mas eles não se sentam à mesa, e isso é porque, aí eles tem um argumento, que o homem asiático é visto através de estereótipos segundo qual ele é o ninja que quer destruir o mundo - que uma ideia antiga da Segunda Guerra Mundial, o perigo amarelo - ou então Samurai, o Kung Fu, porque chinês é asiático. Ou então, ele é efeminado, ele não tem pelo, não tem muito pelo, ele é mais baixo, em média, do que o homem branco, eles não são muito musculosos. Como as emissoras querem que o locutor passe uma ideia de autoridade deixando evidente a mensagem: "Eu estou Ihe falando, ditando essas notícias, passando-as como corretas o homem asiático fica de fora. Mas aí se pode perguntar: "e a mulher asiática então, como é que tem?". Para começar que não são muitas, mas tem algumas, e desde os anos, desde o começo dos anos 80 existe locutora asiática. Isso acontece porque o estereótipo da mulher asiática é o de que ela é, ao mesmo tempo, sedutora e humilde. Então, a proposta de uma locutora asiática não é "eu estou the passando essas notícias com autoridade", é: "eu vou contar isto para você, e espero que você goste", é algo assim; eles jogam com o estereótipo. Mas isso tudo em um livro sobre homens, para ver como com os homens também existe a norma. Mas muitos deles não seguem a norma. Por que? Por causa do recorte de raça e classe e etnia.

Sociologins Plurnis. Então, sigamos, resgatando um pouco da história brasileira. Percebemos que as cotas sociais, de recorte de classe, cotas para indígenas, para a inserção das mulheres no congresso, bem como as cotas para os filhos e filhas de fazendeiros e trabalhadores rurais, conforme a Lei do Boi, de 1968, tiveram um nível de aceitação social muito acima do que vemos em relação às cotas raciais. O que simbolizam as cotas raciais no Brasil? Porque essa resistência da sociedade brasileira em aceitá-las? 
Vânin. O problema não é com as cotas em si, o problema é com a raça, muita gente não sabe sobre a Lei do boi, e eu também não sabia até eu começar a estudar cotas, muita gente não sabe das cotas para mulheres nos partidos políticos, como eu não sabia até 2002. A Veja publicou um artigo em 2006, ódio racial, convite ao ódio racial, dizendo como as cotas universitárias iam levar a um acirramento de animosidade racial no Brasil. Então, em um outro artigo eu escrevi: "Bom, ninguém falou que as cotas para as mulheres nos partidos políticos, vagão para mulheres no metrô, iriam levar a uma guerra de gênero, que as pessoas iam sair, homens e mulheres iam brigar, ninguém falou nisso". Os brasileiros são mais abertos a cotas para deficientes físicos do que para negros, mais abertos a cotas para indígenas do que para negros, mais abertos a cotas sociais - as cotas "não, tinham que ser sociais, por que e o branco pobre?"- do que para negro. Então o problema não é com as cotas, o problema é o racismo, e como, pela primeira vez, tem alguma vantagem em ser negro no Brasil, pela primeira vez com as cotas isso acontece, aí o racismo que se dizia velado aflora. Por que o que está acontecendo? As pessoas, elas tem razão, é claro que se é uma questão de cotas, certo número de vagas vai ser alocado para esses grupos de minorias, vai ser alocado para negros. A questão que fazem é: de onde vão sair essas vagas? Das vagas que anteriormente eram todas para os brancos, e argumenta-se: "não, mas era universal, era para todo mundo", mas a maioria acabava sendo para os brancos. Então, acho que a questão é essa, penso que as cotas fazem as pessoas confrontarem o racismo, por que não é uma questão de justiça? Então vamos acabar com todas as cotas, para mulher, para deficiente físico, para filho de fazendeiro, não é? Em 2006 quando eu estava no Rio fazendo meu pós-doc, meu pós-doc foi esse estudo de histórias de vida de alunos cotistas, encontrei um amigo de faculdade de minha irmã. Quando eu falei para ele sobre meu tema de pesquisa ele logo falou "ah eu sou contra". Para mim não é uma questão de saber se alguém é contra ou à favor das cotas, é um fenômeno que eu estudo como outro qualquer. Então vamos analisar o que estão falando sobre as cotas, o que são as cotas, como elas podem ser comparadas com outras cotas, porque as pessoas falam que é como nos EUA e não é. As políticas públicas não são sobre indivíduos, as políticas públicas são para um grupo, então não interessa se eu precisei ou não, isso é irrelevante.

Sociologins Plurnis. A próxima pergunta trata também da relação Brasil e EUA: considerando que as relações raciais no Brasil seguem uma dinâmica de uma suposta democracia racial, orientada pela ideologia do branqueamento, implícita 
nas estruturas das instituições brasileiras, e nos EUA a gente vê uma dinâmica um pouco diferente de segregação racial direta e explícita, quais as similaridades e diferenças das aplicações de políticas afirmativas no Brasil e nos EUA?

Vânio. Acho que a principal semelhança é que em ambos os países as políticas são compensatórias, vieram para compensar os séculos de exploração do trabalho negro e séculos de exclusão do negro da sociedade civil, e isso é explícito em ambos os países. Eu acho que isso é o que há de mais nos dois programas. Já as diferenças são muitas, porque o público-alvo nos EUA é bem menor do que no Brasil, porque os EUA, como tiveram uma definição de raça como conceito binário é muito mais fácil identificar quem seriam os beneficiários dessa política, embora não seja 100\% perfeito, porque como lá é ascendência, já houve caso nos EUA de pessoas visivelmente brancas pedirem para serem reavaliados. Teve um caso de dois irmãos em Boston, acho que na década de 80 ou no começo da década de 90, que fizeram prova para bombeiro em uma cidade grande dos Estados Unidos e eles não passaram, o que tinha acontecido entre os anos 60 e 80, é que várias cidades tinham modificado os critérios de admissão de bombeiros - não que eles tivessem cotas para bombeiros, porque nunca houve cotas nos EUA - mas eles criaram critérios que davam mais pontos, tipo o sistema da USP. Então, mais pontos para latinos e para negros, porque os latinos em Nova lorque alegaram que certos parâmetros, certos requisitos para ser bombeiro em Nova lorque excluíam os latinos, mas por que? Tem que ter altura " $X$ ". e les argumentaram que o portorriquenho médio não tem essa altura, e por que que o bombeiro tem que ter essa altura $X$ ? Tem que ter essa altura para apagar o fogo? Não tem que ter. Assim foram bem sucedidos e outros lugares adotaram essa política. Então, se a pessoa se declara negra ou latina no formulário de inscrição, quando faz a prova ganha mais pontos. Os dois irmãos se declararam brancos, estava a foto deles lá, brancos. Não passaram. Aí eles tiraram uma foto de uma bisavó do baú, do fundo do baú, que também para mim não tinha nada de negra, para mim era branca também. Dai pode-se pensar: ah, não, mas ela era. Vamos dizer, alguma porcentagem negra, vamos dizer...

Sociologins Plurnis. 32 avos, como é que se falava?

Vânio. Não, o 1/32 avos é de Mississipi, é essa definição, até 1/32 avos é negro. Aí a controvérsia foi essa. Não me lembro se eles foram admitidos ou 
não, mas eles alegaram que eram negros. É algo que também aconteceu na UnB, com gêmeos, onde um foi aceito o outro não foi, mas como é que pode, ser a afrodescendência não tem a ver com a cor da pele, tem a ver com a ascendência. Assim, nos EUA, de modo geral é mais fácil provar que se é negro com o argumento: "Ah eu sou negro, porque eu tenho essa ascendência", e aqui, aqui é mais controverso, por que quem é negro no Brasil? Podemos dizer que é quem a polícia prende, quem é assassinado. $\mathrm{E}$ é verdade.

Sociologins Plurnis. Passando mais para a discussão de gênero, as mulheres negras têm uma participação muito ativa dentro dos movimentos sociais, especialmente o movimento feminista, como você vê a situação atual da luta política dessas mulheres dentro do cenário brasileiro ou estadunidense?

Vânin. Bom, não é minha área, não estudo movimentos feministas, então o que eu vou falar para é impressionista. No Brasil no Brasil eu sei que tem esses grupos, como Geledez e Fala Preta, então eu sei que existe uma militância. Eu sei que a militância negra feminina é muito antiga, a Luisa Main, que é do século XIX, e a Lélia Gonzales, nos anos 70, 80, 90 até ela morrer nos anos 90. Lélia era filósofa, antropóloga, mas também era militante. E hoje em dia, é Edna Rolim. Eu acho que tem questões que são particulares à mulher negra, na sociedade em geral, no movimento feminista e dentro do próprio movimento negro, pois ele, como qualquer outra instituição, tem também o seu lado machista. Então as mulheres negras tem que achar o seu lugar. Nos EUA dos anos 70 quem chamou muita atenção para isso foi a Angela Davis. Tem uma matéria curtinha que saiu numa para a mulher negra, Essence, que, cujo título era "Feminismo é uma coisa de preta", e aí nesse artigo ela falava que as mulheres negras tendem a olhar as instituições, os grupos feministas como uma coisa de mulher branca, primeiro porque a mulher negra não tem tempo para isso, segundo porque as mulheres brancas estão lá reivindicando mais salários, e elas estão reivindicando mais tempo para ficar em casa, porque elas trabalham demais, mas que as mulheres negras têm que entender que as questões feministas também têm a ver com a situação da mulher negra na sociedade. A parte mais radical do movimento por direitos civis nos EUA né, depois que, depois do assassinato de Martin Luther King ficou muito mais... acabou com esse negócio de virar o outro rosto e não violência, a gente vai pegar em armas se necessário, e, que é um movimento que já era paralelo, mas aí com a morte deles ficou mais... 
Sociologins Plurais. Não são os "panteras negras"?

Vânio. Os panteras negras, mas não só eles, como outros indivíduos que o $\mathrm{FBI}$ matou, mas não necessariamente os panteras negras, mas que eram vociferes nessa coisa de "não interessa o que tem que tiver que fazer", a Nation of Islam, Nação do Islã, também é separatista, e dizia "se tiver que pegar em arma a gente pega". Nesse contexto, em uma reunião do movimento negro, uma mulher negra se levantou e perguntou a um dos líderes: "qual é a posição da mulher negra no movimento?", ele respondeu "Prone", ou seja, de bruços, ou seja...

Sociologias Plurais. Dando filhos...

Vânio. Também, ou nem precisava dar filhos, não é? Agora eu estou citando um dos textos que meus aluno leem em Sociologia da Família, falando que mesmo em um grupo oprimido por raça e por classe, a questão de gênero é importante porque, até porque mesmo no caso desses homens, se eles são, eles também são oprimidos pela sociedade, então eles já são menos homens aos olhos da sociedade porque eles não tem tanto poder quanto os homens brancos, então acaba que eles transferem aquela frustração para as pessoas mais próximas deles, ou seja as mulheres deles, então pode acabar sendo mais, sendo machistas mesmo, sexistas com as mulheres, então por isso que a questão do gênero é tão importante entre os negros, porque é mais uma forma de opressão que divide os dois, porque a raça une. A opressão racial une, a opressão por classe une, a opressão por gênero divide.

Sociologins plurais. Bom, além dessas cisões que os movimentos sociais das mulheres negras, com os homens negros, também com as mulheres brancas, entre outras, toda essa movimentação, nós vemos que entre os militantes negros, e também entre os acadêmicos negros, as discussões sobre estética e relações de gênero dividem opiniões, como a professora falou, o gênero divide. Sendo uma discussão que gera um ponto de tensão e que não se conseguiu fazer de maneira mais ampla, mais tranquila. Então a gente fala à partir da fala de uma pedagoga $\mathrm{e}$ cientista social da PUC, a Claudete Alves, que realizou um estudo em 2008, numa pesquisa sobre casamentos inter-raciais e não inter-raciais e que revelou, além da solidão da mulher negra nos grandes centros urbanos, o fato de que essas 
mulheres eram preteridas para os relacionamentos e, entre outras coisas, os homens não tinham preparo e não tinham vontade de falar sobre o assunto. Dessa forma, queremos saber como a professora vê toda essa relação complexa desses casamentos inter-raciais?

Vânin. E é complexo, porque no Brasil nunca houve lei contra, mas houve a prática contra, e como a escravidão no Brasil foi a mais longa das Américas, e como a gente já viu que as escravas não eram donas dos próprios corpos, então o estupro das mulheres, das escravas e depois das ex-escravas, era comum e não era nem considerado estupro, seguindo o pensamento "ué, é minha mesmo, é minha propriedade" e depois da escravidão foi com a empregada doméstica, podemos imaginar quantos homens brasileiros não se iniciaram perderam a sua virgindade com as "Marias". O Teles mostra que em termos de casamento legal, a incidência é menor e é muito mais comum relações sexuais inter-raciais, mas casamentos inter-raciais são mais raros, embora sejam mais comuns aqui do que nos EUA. Nos EUA existiu uma proibição legal contra casamento inter-racial até 1967, duas semanas atrás fez 46 anos da decisão da Suprema Corte, Loving. Nos EUA, no sul principalmente, era muito comum os homens brancos chegarem, pegarem mesmo, e falarem "ela que quis", e daí, "she is a nigger, I'll do whatever I want with her", ou seja, faço o que eu quiser, não era nem crime, mas era crime se casar, e até 1967, acho que eram 19 estados que ainda tinham essa lei, então os Loving que era um homem branco casando com uma mulher negra, que é raridade, é muito mais comum nos EUA um homem negro casar com uma mulher branca do que o contrário. No caso dos Loving o homem era branco, e eles se conheciam desde a adolescência, se casaram em Virginia e logo foram para Washington DC, porque eles sabiam que era contra, que eram criminosos, que estavam violando a lei. Anos depois eles voltaram, de propósito, justamente para contestar essa lei. No geral, nos EUA tem muitos casos assim de mulheres escrevendo e até estudos como as mulheres negras... ah é, tem um estudo sobre fronteiras raciais, racial borders, como as pessoas, como é que, é uma outra maneira de se estabelecer identidades raciais né, como é que você sabe que você é negro? Porque existem barreiras, existem fronteiras, as fronteiras não são geográficas mais, porque 0 ato de 64 acabou com isso, então não é geográfico, mas são fronteiras estabelecidas através da interação, então ela fala, como é que essas fronteiras são mantidas? Porque as pessoas do grupo monitoram com quem as pessoas daquele grupo se interagem, com quem elas interagem, quem elas namoram, com quem elas casam, então 
elas falam que entre os brancos, os brancos monitoram os brancos e os negros monitoram os negros, os brancos monitoram as mulheres brancas, porque a mulher branca é quem mantem a pureza racial, porque ela tem o útero, a criança sai dela.

Sociologins Plurais. Uma nova questão: o pensamento social brasileiro começa fortemente marcado pelos estudos raciais, seja com os primeiros e com as primeiras tentativas dos ensaístas de interpretar a sociedade brasileira, e/ou propor projetos de nação, tais como o Oliveira Vianna, Sérgio Buarque de Holanda, Gilberto Freyre, seja com Florestan Fernandes, numa fase mais científica das Ciências Sociais, bem como através de pensamentos de Fernando Henrique, embora ele diga "esqueçam o que eu escrevi", e Otavio lanni, que ambos trabalharam raça, entre outros, mas hoje essa temática está à parte, fechada nos nichos de pesquisa sobre estudos raciais, ela perdeu espaço dentro da academia. O que você acredita que possa ter acontecido para ter esse deslocamento epistemológico?

Vânio. Bom, mas aí é que está, eu não acho que isso, que isso esteja acontecendo, eu não acho. Eu acho que isso é particular.

Sociologins Plurais. Você acha que isso é localizado?

Vânio. Eu acho que sim, porque o Brasil, o momento que a gente está vivendo agora, é como 1920 com essa questão toda de "nação", é isso que eu falo também no meu livro, que o que está acontecendo é uma nova concepção de nação, porque a questão é: quem são os brasileiros? A maioria agora é afrodescendente. Como Skidmore mostrou que do censo de 1890 para o censo de 1920, a população negra tinha diminuído vertiginosamente, que estatisticamente era impossivel, porque estatisticamente uma população só pode diminuir vertiginosamente por duas variáveis, uma hecatombe, que haja uma mortalidade em massa, ou seja, que muitas pessoas morram antes do tempo esperado ou por causa de emigração, muita gente saindo, diminuiu o censo, que não foi o caso no Brasil naquela época, então o que aconteceu? Os negros emigraram? Não. Tantos assim morreram em 30 anos? Não. Então foi porque muitas mães, muitos lares brasileiros começaram a dizer que eles não eram negros e é as pessoas passaram a dizer "não, mas eu sou moreninho então vou botar branco". 
Sociologins Plurnis. Para finalizar, na sua opinião, o que a professora acha precisa ser debatido academicamente na Sociologia, tanto no Brasil quanto nos EUA, sobre as questões de classe, raça e gênero?

Vânin. Eu vou dar uma resposta radical, eu acho que é impossível estudar ou se formar em Sociologia, seja no Brasil, seja nos EUA, sem estudar classe, é impossível porque vai ter que ler Marx e Weber, Durkheim não falou muito de classe, mas Marx é classe, Weber é continuação, é uma elaboração do conceito de classe no status, então para se formar sociólogo você tem que saber sobre classe nos estudos, mas você não tem necessariamente que saber sobre gênero e sobre raça, então é essa minha resposta, foi uma resposta básica. Tanto aqui quanto lá, o que é necessário é tornar raça e gênero como também matérias obrigatórias, como classe é, porque classe é tão obrigatória que é a norma, quando você estuda teoria sociológica você estuda classe, mas você não estuda na teoria sociológica nem raça, nem gênero. Para voltar como eu comecei a entrevista, ninguém é só classe. Para a maioria das pessoas, eu acho, nos EUA pelo menos, estudam Sociologia, mas não seguem a carreira, a Michele Obama, por exemplo, é formada em Sociologia, na graduação, e depois ela fez Direito, ou seja, a graduação dela é em Sociologia, mas ela não é Socióloga, mas estudou, então como muitas das pessoas que estudam Sociologia não seguem a carreira, então para que estudar Sociologia? Vamos pensar, Sociologia não vai achar a cura para nada, mas o que que a Sociologia ensina a gente, que ferramentas a Sociologia nos dá? A Sociologia nos ensina a pensar criticamente, qualquer coisa que aconteça, "ah, as manifestações", "cadê os, os negros nessa foto?", é isso aí. A Sociologia nos dá imaginação sociológica, que é aquele termo do Wright Mills. Dessa forma, se a pessoa não vai ter nenhuma outra oportunidade de estudar Sociologia, então que ela receba realmente essas ferramentas para ela aplicar na vida dela, "espera aí, isso está acontecendo comigo não é porque eu sou malandro, porque eu sou burra, é porque está tendo uma crise econômica, e muita gente está perdendo o emprego, não sou só eu", "espera aí, não deixaram, é porque eu sou preta? É por isso? Porque eu estou vendo que não tem problemas com os outros", isso é um pensamento crítico, mas se a pessoa fez um curso, ah, de repente fez um curso de introdução à Sociologia, e aí o professor, ou a professora daquela... "ah, não vou lidar com raça e gênero porque é besteira", aí a pessoa nunca é exposta a essas questões. Eu acho que é isso 
Sociologins Plurnis. Obrigada professora Vânia, foi excelente. A Sociologias Plurais agradece a colaboração. 